\title{
Psychotherapeutische diagnostiek revisited: dupliek op de repliek van Jan Jaspers
}

Over de waarde van de psychodiagnostiek in psychotherapeutische context is de laatste tijd veel discussie (zie onder meer Derksen, Egger \& Van der Heijden, 2008; Verbraak, 2007). Ook onze bijdrage over psychotherapeutische diagnostiek in het vorige nummer van dit tijdschrift (Van der Heijden, Derksen \& Egger, 2008) bleek aanleiding te zijn voor een kritische reactie. Even ging er een rilling door ons heen: zou de grote Karl Jaspers, auteur van 'Allgemeine Psychopathologie', pleitbezorger van een hermeneutische en 'verstehende' diagnostiek en verklaard tegenstander van het betekenisloze symptoomturven, beyond the grave, ons artikel bespreken? In onderhavige bijdrage willen wij graag reageren op de repliek van collega Jan Jaspers.

\section{Over de waarde van psychodiagnostiek}

Jaspers (2008) begint zijn repliek in dit nummer met de vraag of testdiagnostiek een waardevolle bijdrage kan leveren aan het werk van psychotherapeuten. Cruciaal daarbij is volgens hem of testdiagnostiek een 'meerwaarde' heeft voor het effect van de behandeling. Afgezien van de gekozen stijlfiguur (de vraag stellen is hem beantwoorden), afgezien ook van de wedervraag of psychotherapie kan bijdragen aan het resultaat van een diagnostisch proces, lijkt het ook ons dat deze kwestie terecht aandacht verdient, maar niet zonder de navolgende verduidelijking.

DRS. P.T. VAN DER HEIJDEN is gezondheidszorgpsycholoog in opleiding tot klinisch psycholoog en werkt bij de Reinier van Arkel Groep te 's-Hertogenbosch. E-mail: P.T.vander.Heijden@RvAGroep.nl.

DR. J.I.M. EGGER is klinisch psycholoog en universitair docent aan de Sectie Klinische Psychologie van de Radboud Universiteit Nijmegen. Hij werkt als P-opleider bij de GGZ Noord- en Midden-Limburg te Venray.

PROF. DR. J.J.L. DERKSEN is klinisch psycholoog en universitair hoofddocent psychodiagnostiek aan de Sectie Klinische Psychologie van de Radboud Universiteit Nijmegen. Tevens is hij verbonden als hoogleraar aan de Vrije Universiteit van Brussel. 
Het is essentieel om bij het beantwoorden van de meerwaarde-vraag de twee fundamentele perspectieven van de psychodiagnostiek te betrekken. Finn en Tonsager (1997) onderscheiden deze twee paradigma's van psychologisch onderzoek in het information gathering model en het therapeutic model. Psychodiagnostiek als information gathering verwijst naar het traditionele model waarin psychologisch onderzoek ten doel heeft informatie te verzamelen ten behoeve van indicatiestelling en behandelplanning en om de behandelaar meer algemeen te ondersteunen bij het nemen van beslissingen over cliënten en het beschrijven van cliënten in termen van bepaalde categorieën en dimensies (Finn \& Tonsager, 1997). Bij psychodiagnostiek volgens het therapeutic model wordt het testpsychologisch onderzoek op zichzelf gezien als werkzame factor (Finn, 2007; Finn \& Tonsager, 1992; Kamphuis \& Finn, 2006). Anders gezegd: psychologisch onderzoek wordt hier gebruikt als kortdurende interventie.

Daar waar de door Jaspers aangehaalde discussie in 'Directieve therapie' (Derksen, Egger \& Van der Heijden, 2008; Verbraak, 2007) uitsluitend betrekking had op het information gathering model van psychologisch onderzoek, wilden wij in ons artikel voor het 'Tijdschrift voor Psychotherapie' juist vooral een lans breken voor het therapeutische aspect. Wij zijn dan ook blij te lezen dat Jaspers het belang hiervan onderschrijft in zijn repliek: 'Dit samenwerkingsmodel waarin de cliënt een actieve rol krijgt toebedeeld verdient zeker meer aandacht van psychotherapeuten.' Wat betreft het therapeutic assessment model is er enige wetenschappelijke evidentie dat dit werkzaam is. In vergelijking met traditioneel psychodiagnostisch onderzoek vergroot therapeutic assessment het zelfvertrouwen van cliënten, het leidt tot verminderde klachten en vergroot de therapietrouw (Ackerman, Hilsenroth, Baity \& Blagys, 2000; Finn \& Tonsager, 1992; Newman \& Greenway, 1997).

Voor het information gathering model ligt dat anders. Tot op heden ontbreekt het inderdaad nog aan onderzoek naar de effectiviteit van een uitvoerige testbatterij op het behandelresultaat. Het gaat dan over de vraag of extra informatie verkregen met psychologisch testonderzoek een unieke, zinvolle bijdrage kan leveren aan de indicatiestelling voor behandeling en daarmee ook aan het uiteindelijke behandelresultaat (treatment utility) (Nelson-Gray, 2003). Het is ingewikkeld om een dergelijke vraag goed te beantwoorden in een RCT, te meer daar het hier omschreven uitvoerige psychologisch onderzoek doorgaans alleen ingezet wordt bij complexe casuïstiek. Daarnaast zou zo'n vraag in eerste instantie ook altijd bestudeerd moeten worden in de context van een gespecificeerde behandeling van een specifieke aandoening en niet van 'behandeling in het algemeen'.

Overigens bestaat een dergelijk bewijs (zoals Jaspers ook aanhaalt) evenmin voor het psychiatrisch onderzoek (Sno, 2008). Ook over de treatment utility van het neurologisch onderzoek of van het standaard lichamelijk onderzoek zijn geen bevredigende resultaten te vinden. Hier is dus nog veel werk te verrichten voor psychologen en dokters. Maar hoewel we moeten streven naar wetenschappelijke onderbouwing van onze methoden, is het ook wat prematuur om alles wat niet aangetoond is middels een RCT in ons vakgebied overboord te gooien. 


\section{Beeldvorming op verschillende niveaus}

Een artikel over psychodiagnostiek in een psychotherapeutisch tijdschrift blijkt onverhoopt ook allerlei bestaande controversen binnen ons mooie vak te doen opborrelen. Jaspers staat stil bij enkele van deze controverses zoals die rondom de betrouwbaarheid en validiteit van de Dynamisch-Theoretische Profielinterpretatie (Eurlings-Bontekoe \& Snellen, 2003), het oneigenlijke gebruik van psychologische tests en enkele beperkingen van de MMPI2. Tevens stipt hij de beperkingen aan van de persoonlijkheidsstoornissen uit DSM-IV (APA, 1994).

Hoewel dit belangrijke thema's zijn binnen ons vak, raken ze naar onze mening niet de kern van het door ons gepubliceerde artikel. Onder Ovidius' motto 'Gutta cavat lapidem, non vi sed saepe cadendo' (de druppel holt de steen uit, niet met geweld, maar door keer op keer te vallen) zullen we niettemin hieronder nog graag kort ingaan op enkele van deze kwesties en wat uitvoeriger stilstaan bij Jaspers kritiek op de MMPI-2.

Jaspers noemt het onderscheid tussen structurele en descriptieve diagnostiek onduidelijk en discutabel. Het doel van structurele diagnostiek is volgens ons juist helder: met behulp van observatie, ontwikkelingsanamnese, eventueel heteroanamnese en een gespecialiseerd diagnostisch interview, vragenlijsten en psychologische tests een diagnostische beschrijving te maken op een meer verklarend niveau. Structurele diagnostiek is vaak geïndiceerd bij complexe problematiek, waaronder persoonlijkheidsproblematiek (Derksen, 2004). Jaspers noemt dit discutabel omdat de validiteit, betrouwbaarheid en temporele stabiliteit van de DSM-IV-persoonlijkheidsstoornissen zeer te wensen over laat (cf. Hummelen, 2008).

Dat Jaspers de gebrekkige validiteit van de DSM-IV-persoonlijkheidsstoornissen in verband brengt met hetgeen wij onder de noemer structurele diagnostiek scharen, is opmerkelijk. De kritiek op de DSM-IV-persoonlijkheidsstoornissen is inderdaad wijdverbreid. In de op deze plaats reeds aangehaalde publicatie van Derksen (2004) worden de problemen met onder meer de validiteit en betrouwbaarheid van de DSM-As-II-categorieën breed uitgemeten. In een recent artikel van Egger, De Mey en Janssen (2007) wordt daarom in plaats van de DSM-diagnostiek een functioneel contextuele diagnostiek voorgesteld om de koppeling naar (psychotherapeutische) behandeling te optimaliseren. Naast een dergelijke aanpak zouden wij ook steeds willen pleiten voor een meer-dimensionele persoonlijkheidsdiagnostiek zoals bijvoorbeeld met de MMPI-2 mogelijk is (zie voor een interessante uitwerking daarvan de recente publicatie van Sellbom, Ben-Porath en Bagby (2008)).

Jaspers bespreekt in dit verband de richtlijnen die door Verheul, Van den Brink, Spinhoven en Haringsma (2000) zijn opgesteld ten behoeve van het zo betrouwbaar mogelijk stellen van een classificatie op As II van DSM-IV. Hij schrijft dat 'de MMPI-2 in dit hele verhaal niet voorkomt'. Dit is niet verwonderlijk omdat de MMPI-2 in het geheel niet bedoeld is voor het stellen van een DSM-IV-As-II-classificatie! Daarvoor kan men zoals voorgesteld in de richtlijnen van Verheul et al. (2000) veel beter een semigestructureerd in- 
terview gebruiken. De richtlijnen waar wij aan het begin van ons artikel naar verwijzen hebben betrekking op het proces van testdiagnostiek zélf: het gedegen gebruik (zij het niet evidence based dan toch best practice) van psychologische tests volgens het hypothese-toetsend model (Derksen, 2004; FernándezBallesteros, De Bruyn, Godoy, Hornke, Ter Laak, Vizcarro, Westhoff, Westmeyer \& Zaccagnini, 2001).

De relevantie van het uitstapje van Jaspers naar de Dynamisch-Theoretische Profielinterpretatie van Eurelings-Bontekoe en Snellen (2003) is ons in dit verband evenmin duidelijk. Derksen (2005) heeft zelf eerder al kritische kanttekeningen gezet bij deze methode. In ons artikel refereren we in het geheel niet aan de collega's Eurelings-Bontekoe en Snellen. Bovendien geeft Jaspers later zelf ook aan dat uit onze bijdrage blijkt dat wij een andere manier van structurele diagnostiek voorstaan dan de Dynamisch-Theoretische profielinterpretatie.

Wat betreft Jaspers kritiek op de casus moeten we erkennen dat deze inderdaad geen dekkende weergave is van de werkwijze die wij proberen uiteen te zetten. Zoals Jaspers zelf ook al oppert is de casus vooral illustratief bedoeld: hij is opgenomen met het oogmerk om het therapeutisch gebruik van een test te demonstreren.

\section{Kritische noten aangaande de MMPI-2}

Dan de kritiek op de MMPI. Aangaande de normering hebben Kloens, Barelds, Luteijn en Schaap (2003) geconstateerd dat de gemiddelde scores van een steekproef eerstelijnscliënten afwijkt van het gemiddelde van de normgroep. Naar onze mening is dat nu juist de toegevoegde waarde van een dergelijke normgroep, mits deze in zekere mate representatief is voor de bevolking. Op die manier kun je onderzoeken in hoeverre de MMPI-2-scores van de betreffende patiënt afwijken van die van de gemiddelde Nederlander. Verder zijn er op het gebied van de MMPI-2 duizenden studies gepubliceerd over de scores van diverse referentiegroepen (in casu patiëntengroepen uit verschillende diagnostische categorieën; zie voor een overzicht Graham (2006)), waaronder ook met Nederlandse patiëntengroepen. Voor recente Nederlandse voorbeelden zie Ronse (2008) en Egger, Gringhuis, Breteler, De Mey, Wingbermuhle, Derksen en Hilberink (2007).

De kwestie van de item-overlap in de klinische schalen is al zo lang bekend als de MMPI-2 zelf. Het is een artefact van de empirische constructie van de klinische schalen. Juist dit artefact heeft geleid tot de ontwikkeling van doeltreffende technieken om tot een goede testinterpretatie te komen (bijvoorbeeld het interpreteren van specifieke combinaties van verhogingen op de klinische schalen, de zogenaamde code types en het beoordelen van de Harris Lingoes subschalen). Zoals Jaspers ook al noemt hebben Tellegen, Ben-Porath, McNulty, Arbisi, Graham en Kaemmer (2003) recentelijk de klinische schalen uit de MMPI-2 geherstructureerd om definitief af te rekenen met deze beperking. In een bijdrage in 'De Psycholoog' hebben wij daar recentelijk uitvoerig aandacht aan besteed en ook enkele psychometrische bevindin- 
gen gepresenteerd over de geherstructureerde klinische schalen (Restructured Clinical scales; RC-schalen) in de Nederlandse normgroep (Van der Heijden, Egger \& Derksen, 2007). Om de doeltreffendheid van de RC-schalen te illustreren hadden we overigens in de eerder besproken casus in ons artikel beter de scores op de RC-schalen kunnen betrekken zoals Finn en Kamphuis (2006) en Wygant en Fleming (2008) dat zeer illustratief hebben gedaan.

Een ander punt van kritiek op de MMPI-2 door Jaspers is dat de schaalindeling van de MMPI zonder onderzoek is overgenomen uit de Verenigde Staten. Dit is niet juist. Voor de klinische schalen (Derksen \& De Mey, 1992; Sloore, Derksen, De Mey \& Hellensbosch, 1996), de Psychopathology Five (Egger, De Mey, Derksen \& Van der Staak, 2003a; 2003b; Egger, Delsing \& De Mey, 2003), en zeer recentelijk ook voor de RC-schalen (Van der Heijden, Egger \& Derksen, 2008) zijn er studies verschenen waarin de parallelliteit van de Amerikaanse en Nederlandse versie is onderzocht. Deze studies laten zien dat er veel overeenkomsten zijn tussen de Amerikaanse en Nederlandse versie van de MMPI-2 als het gaat om interne structuur, betrouwbaarheid en - in mindere mate - de normgegevens.

Zoals Jaspers opmerkt zijn de ontwikkelingen op het gebied van de RCschalen veelbelovend. In dit kader is het wellicht nog aardig om te vermelden dat er zojuist in de Verenigde Staten een geheel nieuwe, verkorte versie van de MMPI-2 beschikbaar is gekomen. Deze verkorte en herziene versie heet de MMPI-2 Restructured Form (MMPI-2 RF; Ben-Porath \& Tellegen, 2008; Tellegen \& Ben-Porath, 2008), telt 338 items en heeft de RC-schalen als uitgangspunt. Bovendien zijn er drie hogere-ordefactoren in opgenomen die beter aansluiten bij dimensionele modellen van persoonlijkheid (Krueger, 1999; Krueger, McGue \& Iacono, 2001; Sellbom et al., 2008).

\section{Tot besluit}

De kern van ons betoog is de therapeutische waarde van psychodiagnostiek: diagnostiek als zinvolle kortdurende therapeutische interventie. Jaspers eindigt zijn repliek met te benadrukken dat de constructieve alliantie tussen psychodiagnostiek en psychotherapie de aandacht van psychotherapeuten verdient. In die zin zitten we op één lijn.

De vaardigheden van psychotherapeuten raken verouderd, omdat er in de huidige opleiding tot psychotherapeut niet of nauwelijks aandacht wordt besteed aan testdiagnostiek. Psychodiagnostiek blijft daarmee beperkt tot het deskundigheidsgebied van de Gezondheidszorgpsycholoog en van de Klinisch psycholoog en dat is een gemiste kans voor de psychotherapeuten. Door een gebrek aan opleiding lopen zij het risico in de valkuilen te stappen waar Jaspers in zijn repliek voor waarschuwt, zoals het oneigenlijke gebruik van psychologische tests. 


\section{Literatuur}

Ackerman, S.J., Hilsenroth, M.J., Baity, M.R., \& Blagys, M.D. (200o). Interaction of therapeutic process and alliance during psychological assessment. Journal of Personality Assessment, 75, 82-109.

American Psychiatric Association (1994). Diagnostic and statistical manual of mental disorders (4th ed.). Washington, DC: American Psychiatric Association.

Ben-Porath, Y. S., \& Tellegen, A. (2008). MMPI-2-RF User's Guide for Reports. Minneapolis, $\mathrm{MN}$ : University of Minnesota Press.

Butcher, J.N., Dahlstrom, W.G., Graham, J.R., Tellegen, A., \& Kaemmer, B. (1989). Minnesota Multiphasic Personality Inventory-2 (MMPI-2): Manual for administration and scoring. Minneapolis: University of Minnesota Press.

Derksen, J.J.L (2004). Psychologische diagnostiek. Enkele structurele en descriptieve aspecten. Nijmegen: PEN Test Publishers.

Derksen, J.J.L. (2005). Psychodiagnostiek ter discussie. De Psycholoog, 40(6), 333-335.

Derksen, J.J.L., \& De Mey, H.R.A. (1992, May). U.S. and Dutch norms for the MMPI-2: A comparison. Paper presented at the 27 th Annual Symposium on Recent Developments in the Use of the MMPI-2/MMPI-A Workshop and Symposia, Minneapolis, MN.

Derksen, J., De Mey, H., Sloore, H., \& Hellenbosch, G. (2006). MMPI-2: Handleiding bij afname, scoring en interpretatie. Tweede, gewijzigde uitgave. Nijmegen: PEN Test Publishers.

Derksen, J.J.L., Egger, J.I.M., \& Van der Heijden, P. (2008). Van oude misverstanden en stormen die voorbij gaan: Een reactie op Verbraak en Lima et al. Directieve Therapie, 28, 66-74.

Egger, J.I.M., De Mey, H.R.A., \& Janssen, G. (2007). Assessment of executive functioning in psychiatric disorders: Functional analysis as the ouverture of treatment. Clinical Neuropsychiatry, 4, 83-90.

Egger, J.I.M., Gringhuis, M., Breteler, M.A., De Mey, H.R.A., Wingbermuhle, E., Derksen, J.J.L., \& Hilberink, S. (2007). MMPI-2 clusters of alcohol-dependent patients and the relation to Cloninger's temperament-character inventory. Acta Neuropsychiatrica, 19, 238243.

Egger, J., De Mey, H.R.A., Derksen, J.J.L., \& van der Staak, C.P.F. (2003a). Cross-cultural replication of the five-factor model and comparison of the NEO-PI-R and MMPI-2 PSY-5 scales in a Dutch psychiatric sample. Psychological Assessment, 15, 81-88.

Egger, J., De Mey, H., Derksen, J., \& van der Staak, C. (2003b). MMPI-2 and MCMI-III scores among Dutch inpatient substance abusers: Assessing correspondence and crosscultural equivalence. Current Psychology: Developmental, Learning, Personality, Social, 22, $117-124$.

Egger, J.I.M., Delsing, P.A.M., \& De Mey, H.R.A. (2003). Differential diagnosis using the MMPI-2: Goldberg's index revisited. European Psychiatry, 18, 409-411.

Eurelings-Bontekoe, E.H.M., \& Snellen, W. (red.) (2003). Dynamische persoonlijkheidsdiagnostiek. Lisse: Swets \& Zeitlinger.

Fernández-Ballesteros, R., De Bruyn, E.E.J., Godoy, A., Hornke, L.F., Ter Laak, J., Vizcarro, C., Westhoff, K., Westmeyer, H., \& Zaccagnini, J.L. (2001). Guidelines for the Assessment Process (GAP): A Proposal for Discussion. European Journal of Psychological Assessment, 17(3), 187-200. 
Finn, S.E. (1996). Manual for using the MMPI-2 as a therapeutic Intervention. Minneapolis: University of Minnesota Press.

Finn, S.E. (2007). In our clients shoes. Theory and Techniques of Therapeutic Assessment. Mahwah, NJ: Lawrence Erlbaum Associates.

Finn, S.E., \& Kamphuis, J.H. (2006). The MMPI-2 Restructured Clinical (RC) scales and restraints to innovation, or 'What have they done to my song?' Journal of Personality Assessment, 87, 202-210.

Finn, S.E., \& Tonsager, M.E. (1992). Therapeutic effects of providing MMPI-2 test feedback to college students awaiting therapy. Psychological Assessment, 4, 278-287.

Finn, S.E., \& Tonsager, M.E. (1997). Information-Gathering and Therapeutic Models of Assessment : Complementary Paradigms. Psychological Assessment, 9, 374-385.

Graham, J.R. (2006). MMPI-2: Assessing personality and psychopathology (4th edition). New York: Oxford University Press.

Heijden, P.T. van der, Derksen, J.J.L., \& Egger, J.I.M. (2008). Psychotherapeutische diagnostiek: naar een constructieve alliantie. Tijdschrift voor Psychotherapie, 34, 294-303.

Heijden, P.T. van der, Egger, J.I.M., \& Derksen, J.J.L. (2007). Chirurgische ingrepen in de MMPI-2: Komt de patiënt versterkt uit de narcose? De Psycholoog, 42, 589-597.

Heijden, P.T. van der, Egger, J.I.M., \& Derksen, J.J.L. (2008). Psychometric Evaluation of the MMPI-2 Restructured Clinical Scales in Two Dutch Samples. Journal of Personality Assessment, 90, 456-464.

Hummelen, J.W. (2008). Weg met het concept persoonlijkheidsstoornis. Van symptoom via context naar functiediagnostiek. $M G v, 63,485-495$.

Jaspers, J.P.C. (2008). Psychotherapeutische diagnostiek: over de toegevoegde waarde van testdiagnostiek. Tijdschrift voor Psychotherapie, 35, dit nummer.

Kamphuis, J.H., \& Finn, S.E. (2006). Therapeutische psychodiagnostiek: Het samenwerkingsmodel van Finn. In: De Ruiter, C., \& Hildebrand, M. (Red.). Handboek psychodiagnostiek: Van testmethode naar toepassing. Amsterdam: Harcourt Assessment BV.

Kloens, G.J., Barelds, D.P.H., Luteijn, F., \& Schaap, C.P.D.R. (2003). De MMPI-2 in de eerste lijn. Diagnostiek-wijzer, 6, 88-104.

Krueger, R. F. (1999). The structure of common mental disorders. Archives of General Psychiatry, 56, 921-926.

Krueger, R.F., McGue, M. \& Iacono, W.G. (2001). The higher-order structure of common DSM mental disorders: internalization externalization and their connections to personality. Personality \& Individual Differences, 30, 1245-1259.

Nelson-Gray, R.O. (2003). Treatment utility of psychological assessment. Psychological Assessment, 15, 521-531.

Newman, M.L., \& Greenway, P. (1997). Therapeutic effects of providing MMPI-2 feedback to clients at a university counselling service: A collaborative approach. Psychological Assessment, 9, 122-131.

Ronse, E. (2008). Helpt de MMPI-2 een autismespectrumstoornis opsporen? Wetenschappelijk Tijdschrift Autisme, 1, 16-23.

Sellbom, M., Ben-Porath, Y.S., \& Bagby, R.M. (2008). Personality and Psychopathology: Mapping the MMPI-2 Restructured Clinical (RC) scales onto the Five Factor Model of personality. Journal of Personality Disorders, 22, 291-312.

Sloore, H., Derksen, J., De Mey, H., \& Hellensbosch, G. (1996). The Flemish/Dutch version of the MMPI-2: Development and adaptation of the inventory for Belgium and The 
Netherlands. In: J. M. Butcher (Ed.). International adaptations of the MMPI-2: Research and clinical applications (pp. 329-349). Minneapolis: University of Minnesota Press.

Sno, H.N. (2008). Het psychiatrisch onderzoek tegen de achtergrond van evidence-based medicine. Tijdschrift voor Psychiatrie, 50, 353-358.

Tellegen, A., \& Ben-Porath, Y.S. (2008). MMPI-2-RF Technical Manual. Minneapolis, MN: University of Minnesota Press.

Tellegen, A., Ben-Porath, Y.S., McNulty, J.L., Arbisi, P.A., Graham, J.R., \& Kaemmer, B. (2003). The MMPI-2 Restructured Clinical (RC) scales: Development, validation and interpretation. Minneapolis: University of Minnesota Press.

Verheul, R., Brink, W. van den, Spinhoven, Ph., \& Haringsma, R. (2000). Richtlijnen voor klinische diagnostiek van DSM-IV-persoonlijkheidsstoornissen. Tijdschrift voor Psychiatrie, 42, 409-422.

Verbraak, M. (2007). Misverstanden en mythes. Persoonlijkheidstests dragen bij tot betere resultaten van psychologische behandelingen. Directieve Therapie, 27(3), 205-207.

Wygant, D. B. \& Fleming, K.P. (2008). Clinical Utility of the MMPI-2 Restructured Clinical (RC) Scales in Therapeutic Assessment: A case Study. Journal of Personality Assessment, go(2), 110-118. 